\title{
The Circular Economy of E-Waste in the Netherlands: Optimizing Material Recycling and Energy Recovery
}

\author{
Laura Golsteijn and Elsa Valencia Martinez \\ PRé Consultants bv, Stationsplein 121, 3818 LE Amersfoort, Netherlands \\ Correspondence should be addressed to Laura Golsteijn; golsteijn@pre-sustainability.com
}

Received 9 February 2017; Accepted 3 April 2017; Published 31 July 2017

Academic Editor: Livia Arcioni

Copyright (c) 2017 Laura Golsteijn and Elsa Valencia Martinez. This is an open access article distributed under the Creative Commons Attribution License, which permits unrestricted use, distribution, and reproduction in any medium, provided the original work is properly cited.

\begin{abstract}
In the Netherlands, waste electric and electronic equipment (e-waste) is an important point for discussion on the circular economy agenda. This paper shows the Dutch example of how "waste" can be turned into a resource, and the climate change benefits from appropriate collection and recycling. It describes the avoided emissions of $\mathrm{CO}_{2}$-equivalents due to e-waste recycling and appropriate removal and destruction of $(\mathrm{H}) \mathrm{CFCs}$ contained in cooling and freezing appliances. Six different e-waste categories were included, and the results of 2016 were compared to previous years (2009-2015). In 2016, 110,000 tonnes of e-waste were collected. 80\% of this was recycled to useful materials. Additionally, it resulted in $17 \%$ energy recovery. That year, the recycling of e-waste and the removal of $(\mathrm{H}) \mathrm{CFKs}$ resulted in approximately 416,000 tonnes of avoided emissions of $\mathrm{CO}_{2}$-equivalents. Although the phasing out of cooling and freezing appliances with $(\mathrm{H}) \mathrm{CFKs}$ led to a general decrease in the quantity of avoided $\mathrm{CO}_{2}$ emissions over time, removal of $(\mathrm{H}) \mathrm{CFKs}$ still explained most of the avoided $\mathrm{CO}_{2}$ emissions. Material recycling appeared particularly beneficial for cooling and freezing appliances and small and large household appliances. The paper ends with reasons to further close the loop and ways forward to do so.
\end{abstract}

\section{Introduction}

In a circular economy, the intention is to produce no waste or pollution. Instead, products, parts, and materials are used, cared for, repaired, reused, and recycled as much as possible [1]. This is intended to be the preferred alternative to the dominant economic development of "take, make, and dispose" [2]. The options to close the loop and practice a circular economy range from smarter product design and use [3], via product (or parts) life extension, to useful applications [4]. Yet, the circular economy is best known for the so called 3R Principles: Reduction, Reuse, and Recycle [5]. There is a lively debate going on in society about the attractiveness of a circular economy for different stakeholders. The advantages are not just related to environment and health, but can also include economic growth and employment [6]. In December 2015, the European Commission adopted an ambitious circular economy package to stimulate sustainable economic growth [7].

Also in the Netherlands, circular economy is high on the agenda. An important topic for discussion is the waste electric and electronic equipment (e-waste). Special attention is paid to smart product design as a way to reduce resource consumption and energy use, facilitate reuse of product components, and extent the product lifetime [8]. Additionally, the recovery of expensive and scarce materials from e-waste represents a significant opportunity for the environment and the economy. Therefore, Dutch governmental regulations aiming to maximize the reuse of discarded equipment containing valuable resources should be maximized. E-waste can be recycled at a minimum standard (shredding) or a high standard (WEEELABEX requirements [9]), resulting in large differences in the level of recycling between countries. To stimulate material recovery and to decrease the emission of hazardous substances, high standard recycling is mandatory in the Netherlands.

The collection and recycling of e-waste in the Netherlands is well organised by nonprofit organisation Wecycle, on behalf of 1,500 producers and importers [10]. Wecycle was one of the first organisations in Europe, active since 1999. The organisation works together with many parties like municipalities, shops, and installation companies. Next to that, Wecycle 
TABLE 1: Avoided use of new material and the associated correction for losses per recycled material.

\begin{tabular}{|c|c|c|}
\hline Recycled material & $\begin{array}{l}\text { Avoided use of new material } \\
\text { (ecoinvent process) }\end{array}$ & $\begin{array}{c}\text { Correction for losses } \\
(\% \text { extra needed }) \\
\end{array}$ \\
\hline Aluminium & Aluminium, primary, ingot $\{$ RoW $\} \mid$ market for $\mid$ Alloc Rec & $3 \%$ \\
\hline Iron and steel & $\begin{array}{l}\text { Steel, low-alloyed }\{\text { RER }\} \text { | steel production, converter, low-alloyed | Alloc } \\
\qquad \operatorname{Rec}\end{array}$ & $10.5 \%$ \\
\hline Zinc & Zinc $\{$ GLO $\} \mid$ market for $\mid$ Alloc Rec & $90.3 \%$ \\
\hline Copper & Copper concentrate $\{$ RER $\}$ | copper mine operation | Alloc Rec & No losses \\
\hline Polystyrene (PS) & Petroleum $\{$ GLO $\} \mid$ market for $\mid$ Alloc Rec & No losses \\
\hline Polyethylene (PE) & Petroleum $\{$ GLO $\} \mid$ market for $\mid$ Alloc Rec & No losses \\
\hline ABS & Petroleum $\{$ GLO $\} \mid$ market for $\mid$ Alloc Rec & No losses \\
\hline Glass used for glass recycling & Flat glass, uncoated $\{$ RER $\}$ | production | Alloc Rec & $20.7 \%$ \\
\hline Glass used for concrete production & $\begin{array}{l}39 \% \text { sand }\{\text { GLO }\} \mid \text { market for } \mid \text { Alloc Rec, and } \\
61 \% \text { gravel, crushed }\{\text { GLO }\} \mid \text { market for } \mid \text { Alloc Rec }\end{array}$ & No losses \\
\hline
\end{tabular}

organises appropriate removal and destruction of (hydro) chlorofluorocarbons (in short referred to as (H)CFCs) in cooling and freezing appliances, which are known for their ozone layer depletion capabilities and their high contribution to global warming.

The present paper assesses the environmental benefits of Wecycle's activities. It describes the climate change performance of e-waste recycling and appropriate removal and destruction of $(\mathrm{H}) \mathrm{CFCs}$. Six different e-waste categories are taken into account, and the results of 2015 are compared to previous years (2009-2014). Additionally, it is shown how "waste" can be turned into a resource, and what other strategies can be used to further close the loop.

\section{Materials and Methods}

The yearly climate change performance of Wecycle's activities was determined with use of a life cycle approach. The avoided $\mathrm{CO}_{2}$ emissions due to the recycling of e-waste were estimated on the basis of the avoided use of new materials. For example, the avoided environmental impacts of copper recycling are estimated on the basis of the environmental impacts of copper production (for details see Table 1). In order to take into account the lost resources when recycling a material, a material-specific correction for losses was applied. Recycled materials included aluminium, copper, iron, zinc, glass (used for production of glass and concrete), and plastics (ABS, $\mathrm{PE}$, and PS). In addition, the climate change performance of appropriate removal and destruction of $(\mathrm{H}) \mathrm{CFC}$ contained in cooling and freezing appliances was quantified with use of the substance-specific Global Warming Potential (GWP, expressed in $\mathrm{kg} \mathrm{CO}_{2}$-equivalents per $\mathrm{kg}$ refrigerant) during a period of 100 years.

The life cycle modeling was done in SimaPro [11]. Information on the collected amounts of material type per e-waste category was collected with the database application, WFRepTool [12]. This is a tool that can be used to calculate recycling and recovery rates for e-waste in a transparent, traceable manner, in accordance with what is required in the international WEEELABEX standard [9]. Six e-waste categories were included: large household appliances (LHHA),
TABLE 2: Quantities collected e-waste per year, and the amount of refrigerants removed from cooling and freezing appliances in an environmentally responsible way.

\begin{tabular}{lcc}
\hline Year & $\begin{array}{c}\text { Collected amount of e-waste } \\
\text { (tonnes) }\end{array}$ & $\begin{array}{c}\text { Removed amount of } \\
\text { refrigerants (tonnes) }\end{array}$ \\
\hline 2009 & 83,000 & 120 \\
2010 & 106,000 & 100 \\
2011 & 110,000 & 130 \\
2012 & 121,000 & 110 \\
2013 & 115,000 & 125 \\
2014 & 111,000 & 107 \\
2015 & 110,000 & 85 \\
2016 & 110,000 & 89 \\
\hline
\end{tabular}

small household appliances (SHHA), cooling and freezing appliances (CF), televisions (CRT), flat panel displays (FPD), and energy saving light bulbs (LAMP). Life cycle inventory data were collected from the ecoinvent 3.1 database [13]. This includes, for example, data about raw materials supplies and emissions related to the production of the different materials. For the calculation of the carbon footprint the IPCC 2013 method was used [14].

\section{Results and Discussion}

3.1. Collected E-Waste. Through the collection of discarded electrical appliances and energy saving lighting, large quantities of e-waste have been recycled in the Netherlands. From 2009 until 2012, the collected amount of e-waste increased yearly. The last few years the amount stabilizes around 110,000 tonnes.

Table 2 shows the collected amounts of e-waste per year and the removed amounts of refrigerants.

3.2. Useful Applications. Following the principles of a circular economy, what used to be regarded as "waste" is now turned into a resource (see Figure 1). In 2016, $80 \%$ of discarded ewaste was recycled to useful materials in the Netherlands. 


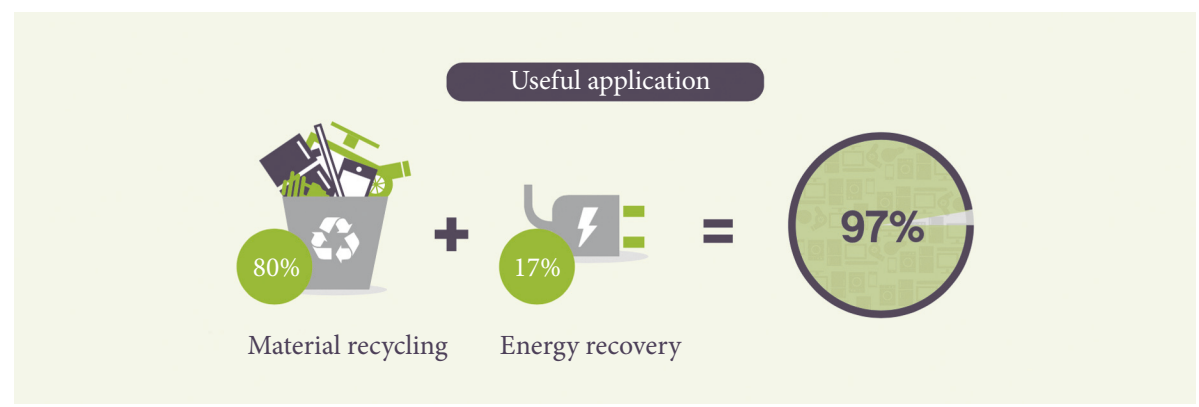

Figure 1: In 2016, e-waste collection in the Netherlands led to $80 \%$ material recycling and 17\% energy recovery.

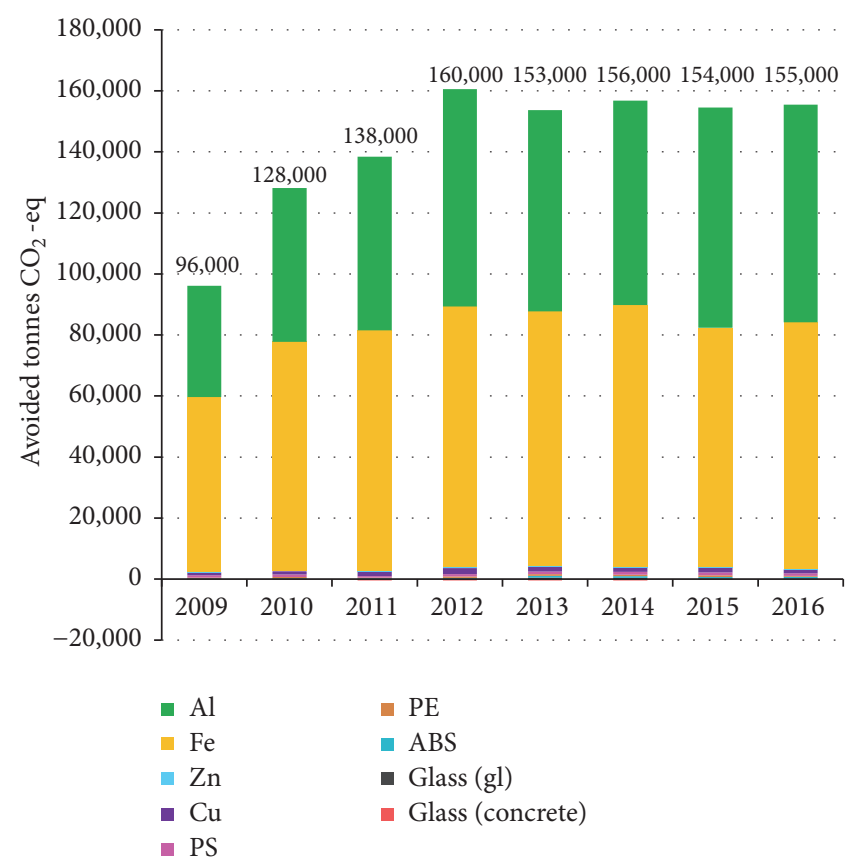

FIGURE 2: Avoided $\mathrm{CO}_{2}$ emissions from material recycling in tonnes $\mathrm{CO}_{2}$-equivalents, per material, for the period 2009-2016. Numbers are rounded.

In addition, the collection of e-waste resulted in $17 \%$ energy recovery.

3.3. Avoided Climate Change. The avoided $\mathrm{CO}_{2}$ emissions of material recycling were estimated on the basis of avoided production of new materials. In 2016, the material recycling of 110,000 tonnes of e-waste resulted in an avoided total of 155,000 tonnes of $\mathrm{CO}_{2}$-equivalents. This was mainly due to the recycling of aluminium (46\%) and iron (52\%). Since 2009, these two materials have always been the major contributors to the avoided amount of $\mathrm{CO}_{2}$-equivalents (see Figure 2), due to the collected quantities. Small contributions came from copper $(1 \%)$, zinc $(0.02 \%)$, polystyrene $(1 \%)$, polyethylene $(0.2 \%)$, ABS $(0.3 \%)$, and glass used for glass recycling $(0.2 \%)$. In contrast, glass used for concrete production resulted in real (disadvantageous) emissions of $\mathrm{CO}_{2}$-equivalents, rather than avoided emissions $(-0.1 \%)$.

Next to the material recycling, refrigerants were removed from cooling and freezing appliances in an environmentally responsible way. In 2016, there was 89 tonnes of refrigerants in total, including R11 (trichlorofluoromethane), R12 (dichlorodifluoromethane), R13 (chlorotrifluoromethane), R22 (chlorodifluoromethane), R114 (dichlorotetrafluoroethane), R125, R134a, R141b, cyclopentane, isopentane, propane, and butane. Their removal corresponded to more than 261,000 tonnes of avoided $\mathrm{CO}_{2}$-equivalents.

Figure 3 shows the origin of avoided $\mathrm{CO}_{2}$ emissions. It is clear that the removal of $(\mathrm{H}) \mathrm{CFK}$ s explained the major part of the total avoided $\mathrm{CO}_{2}$ emissions throughout the years. Yet, in general, there was a decrease in the quantity of avoided $\mathrm{CO}_{2}$ emissions over time, namely, from about $84 \%$ of the total avoided $\mathrm{CO}_{2}$ in 2009 to $60 \%$ in 2015 . This is related to the phasing out of cooling and freezing appliances with $(\mathrm{H}) \mathrm{CFKs}$. Figure 3 also shows that material recycling of cooling and freezing appliances contributed $9 \%$ to the total avoided $\mathrm{CO}_{2}$ emissions in 2016, energy saving light bulbs $0.2 \%$, televisions $1.3 \%$, flat panel displays $1.2 \%$, small household appliances $13 \%$, and large household appliances $13 \%$.

Adaptations in technology can influence the avoided $\mathrm{CO}_{2}$ emissions. Next to that, uncertainty in the measurements of 


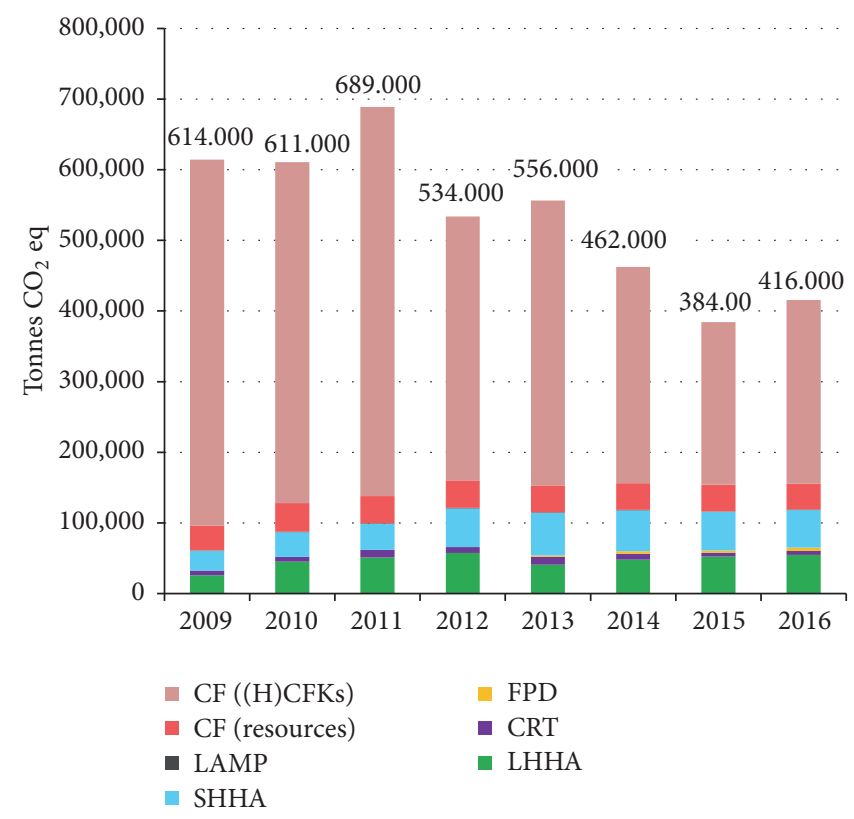

FIgure 3: Total avoided $\mathrm{CO}_{2}$ emissions in tonnes $\mathrm{CO}_{2}$-equivalents, per category e-waste, for the period 2009-2016. The contribution of (H)CFKs and raw materials of CFs is presented separately. Numbers are rounded.

both the collected amounts of e-waste and in the amounts of recycled materials and removed $(\mathrm{H}) \mathrm{CFK}$ caused fluctuations in Figure 3.

3.4. Further Closing of the Loop. The results shown before illustrate the environmental benefits for our climate related to the successful collection and recycling of e-waste, and the appropriate removal and destruction of $(\mathrm{H}) \mathrm{CFC}$ contained in cooling and freezing appliances. Yet, the opportunities to further close the loop should be explored for multiple reasons.

First of all, perhaps the most obvious reason is that even maximum recycling cannot cover all European demand for resources [15]. Currently, recycling covers only a small proportion of the European demand for resources. And even if all waste could be recycled, the material consumption would not be fully met. E-waste is among the recycling categories with the lowest coverage of the demand, both in current and in maximum recycling scenarios. Since the economic growth driven by ever increasing material consumption is unsustainable, a solution to decouple economic growth from material consumption is needed [2].

A second argument to further close the loop is the risk of environmental pollution and human health damage by a variety of toxic substances in e-waste when disposal protocols are meticulously managed [16]. The gap between the amount of electric and electronic equipment "put on market" and the official recycling rates of e-waste is referred to as "complementary e-waste streams." Most of these complementary e-waste streams originate from the economic value that ewaste has as a result of the metal components. This part ends up at scrap and metal traders among which there is a large number of not registered parties, responsible for unfair competition with the recycling companies who invest in high standard recycling. Moreover, this trade leads to transport of e-waste to developing countries where recycling is based on manual processes in backyards of residential properties [16]. The minimum standard recycling (shredding) of the complementary e-waste streams leads to a low grade metal mix which is melted to produce low grade iron or is upgraded elsewhere. Many case studies from e-waste recycling plants confirmed that the toxic chemicals such as heavy metals and POPs have and continue to contaminate the soil, water, and air [16]. Additionally, trading old scrap should be considered as the loss of a key resource which will ultimately also affect the semifinished products industry [17].

Thirdly, optimizing e-waste collection can further reduce global warming. The fact is that despite of the available collection facilities, during the last few years, an additional $30 \%$ of e-waste was found in the Dutch municipal waste [18]. Assuming that the composition of the waste equipment in the municipal waste is the same as that of the separately collected e-waste, the potential extra benefit for the environment is in the order of $1.2 \cdot 10^{5}$ tonnes of avoided emitted $\mathrm{CO}_{2}$ equivalents. To provide some reference, this potential amount of avoided $\mathrm{CO}_{2}$-equivalent emissions corresponds with the yearly emission of about $4.1 \cdot 10^{4}$ gasoline cars in the Netherlands (assuming an average distance of 15,000 km per year and using a direct emission of $194 \mathrm{~g} \mathrm{CO}_{2}$ equivalents per $\mathrm{km}$ [19]).

As already indicated before, another advantage of the circular economy may be found in employment [6]. Recycling creates more jobs at higher income levels than land filling or incinerating waste [15]. Municipalities collecting discarded electric and electronic equipment can boost their local employment by facilitating local sorting and disassembly before sending the e-waste to specialised recycling companies. Initiatives exploring this opportunity have 
already been set up by Wecycle at several places in the Netherlands.

In the short term, the way forward to further close the loop lies among others in improving the network creation and communication with municipalities, retailers, and citizens. By increasing awareness and trust in the collection system, collection results can be improved. In the long term, the way forward to further close the loop lies in the quality of the recycled material. The circular economy will only be successful if the quality of the recycled material can be guaranteed and maintained. This provides good input for the discussion on the EU's existing regulatory structures. Hazardous chemicals must be prevented from reentering the cycle, like for instance when toxic flame retardants from electronic waste were recycled into children's toys [20]. The job for regulators and product designers is to keep in mind that a toxicity estimate may increase over time with advancing insights. In order to create a future-focused and sustainable circular economy, UK charity CHEM Trust provides the following recommendations regarding the safe use of chemicals [21]: to anticipate a high level of recycling in the product design; to evaluate for the use of EU restricted chemicals; and to evaluate for the use of hazardous chemicals that were legal at the time of product manufacturing, but are now restricted or banned. Moreover, the customers' trust in recycled material deserves great attention. If customers are confident in the collection system and the quality of recycled material, the demand of virgin materials can be minimized and the circular economy will be successful.

\section{Conclusions}

The present paper uses a life cycle approach to explain the climate change benefits of the e-waste collection and associated recycling activities in the Netherlands. Following the principles of a circular economy, what used to be regarded as "waste" can be turned into a resource. The paper describes the avoided emissions of $\mathrm{CO}_{2}$-equivalents due to e-waste recycling and appropriate removal and destruction of $(\mathrm{H}) \mathrm{CFCs}$ contained in cooling and freezing appliances in the period 2009-2016. In 2016, 80\% of discarded ewaste was recycled to useful materials in the Netherlands. In addition, the collection of e-waste resulted in $17 \%$ energy recovery. Material recycling appeared particularly beneficial for cooling and freezing appliances, and small and large household appliances. The material recycling of aluminium and iron resulted in the largest share of avoided emissions of $\mathrm{CO}_{2}$-equivalents. Yet, throughout the years, the appropriate removal of $(\mathrm{H}) \mathrm{CFKs}$ explained the major part of the total avoided $\mathrm{CO}_{2}$ emissions. Because of the phasing out of cooling and freezing appliances with $(\mathrm{H}) \mathrm{CFKs}$, a general decrease in the quantity of avoided $\mathrm{CO}_{2}$ emissions over time could be observed.

The results shown in this paper illustrate the environmental benefits for our climate related to the successful collection and recycling of e-waste, and the appropriate removal and destruction of $(\mathrm{H}) \mathrm{CFCs}$ contained in cooling and freezing appliances. Yet, the opportunities to further close the loop should be explored in order to (1) meet the
European material demand; (2) prevent harmful effects to the environment and human health from unregistered low standard recycling (shredding), (3) further reduce global warming by preventing the discarding of e-waste in municipal waste, and (4) boost employment. Ways forward to close the loop lie predominantly in improving collection results through better communication with municipalities, retailers, and citizens and in guaranteeing and maintaining the quality of the recycling material.

\section{Conflicts of Interest}

The authors declare no conflicts of interest.

\section{Acknowledgments}

This paper benefited from discussions with Hendrik Bijker and Ted van Hintum (both Wecycle) and Bart in 't Groen (DNV GL).

\section{References}

[1] Ellen MacArthur Foundation, Towards the Circular EconomyEconomic and Business Rationale for an Accelerated Transition, vol. 1, 2013, https://www.ellenmacarthurfoundation.org/assets/ downloads/publications/Ellen-MacArthur-Foundation-Towards-the-Circular-Economy-vol.1.pdf.

[2] D. Ness, "Sustainable urban infrastructure in China: towards a factor 10 improvement in resource productivity through integrated infrastructure systems," International Journal of Sustainable Development and World Ecology, vol. 15, no. 4, pp. 288301, 2008.

[3] K. Ramani, D. Ramanujan, W. Z. Bernstein et al., "Integrated sustainable life cycle design: a review," Journal of Mechanical Design, Transactions of the ASME, vol. 132, no. 9, Article ID 091004, 15 pages, 2010.

[4] SER, Working on a Circular Economy. No Time to Lose, Social and Economic Council of the Netherlands, The Hague, Netherlands, 2016, (Dutch).

[5] S.-I. Sakai, H. Yoshida, Y. Hirai et al., "International comparative study of 3R and waste management policy developments," Journal of Material Cycles and Waste Management, vol. 13, no. 2, pp. 86-102, 2011.

[6] P. Ghisellini, C. Cialani, and S. Ulgiati, "A review on circular economy: the expected transition to a balanced interplay of environmental and economic systems," Journal of Cleaner Production, vol. 114, pp. 11-32, 2016.

[7] European Commission, "Closing the loop-An EU action plan for the Circular Economy," 2015, http://eur-lex.europa.eu/legalcontent/EN/TXT/?qid=1453384154337\&uri=CELEX:52015DC0614.

[8] Sociaal-Economische Raad (SER), Werken aan een Circulaire Economie: Geen Tijd te Verliezen, 2016.

[9] WEEELABEX Standards, http://www.weeelabex.org/standards/.

[10] Wecycle, https://www.wecycle.nl/.

[11] SimaPro LCA Software, https://simapro.com/.

[12] WF-RepTool, http://www.wf-reptool.org/index.php/home.

[13] “Ecoinvent version 3.1, http://www.ecoinvent.org/. 
[14] Intergovernmental Panel on Climate Change (IPCC), IPCC Fifth Assessment Report-Climate Change 2013: The Physical Science Basis, 2013, http://www.ipcc.ch/report/ar5/wg1/.

[15] "Earnings, jobs and innovation: the role of recycling in a green economy," Tech. Rep., European Environment Agency, the role of recycling in a green economy. EEA Report No 8/2011, 2011.

[16] P. Kiddee, R. Naidu, and M. H. Wong, "Electronic waste management approaches: an overview," Waste Management, vol. 33, no. 5, pp. 1237-1250, 2013.

[17] E. Sevigné-Itoiz, C. M. Gasol, J. Rieradevall, and X. Gabarrell, "Environmental consequences of recycling aluminum old scrap in a global market," Resources, Conservation and Recycling, vol. 89, pp. 94-103, 2014.

[18] Data on consumer behaviour obtained via personal communication with Wecycle (Hendrik Bijker).

[19] L. C. Den Boer, F. P. E. Brouwer, and H. P. van Essen, STREAMStudie naar Transport Emissies van Alle Modaliteiten, CE Delft, Delft, The Netherlands, 2008.

[20] IPEN, "Toxic Toy or Toxic Waste: Recycling POPs into New Products," Press release, 2015, http://www.ipen.org/news/toxictoy-or-toxic-waste-recycling-pops-new-products.

[21] CHEM Trust, Circular Economy and Chemicals: Creating a Clean and Sustainable Circle (Policy Briefing), 2015. 


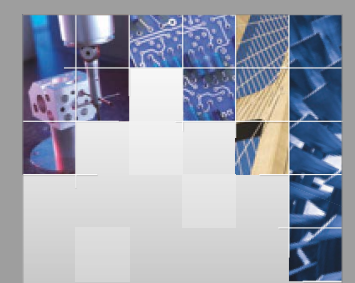

\section{Enfincering}
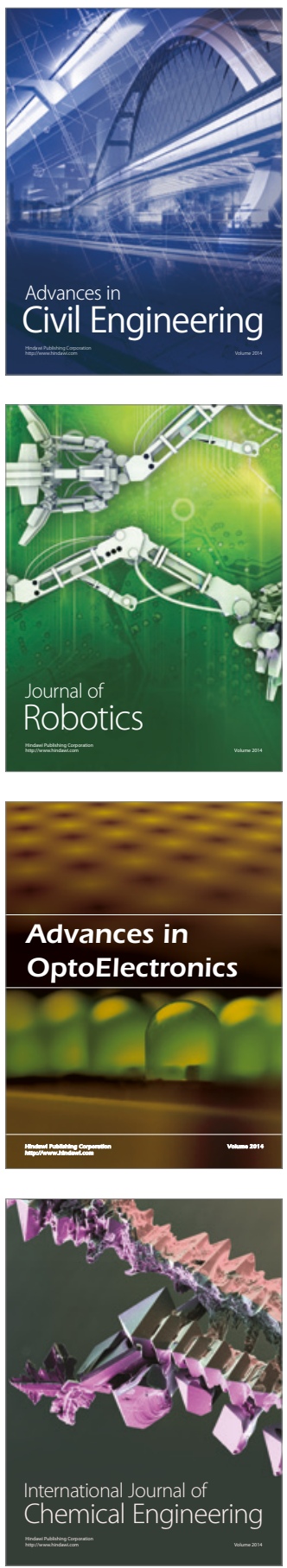

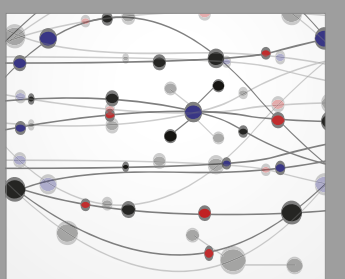

The Scientific World Journal

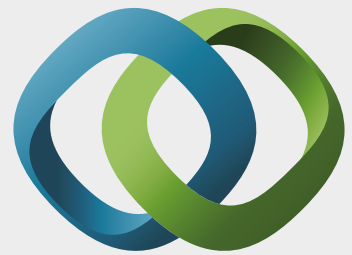

\section{Hindawi}

Submit your manuscripts at

https://www.hindawi.com
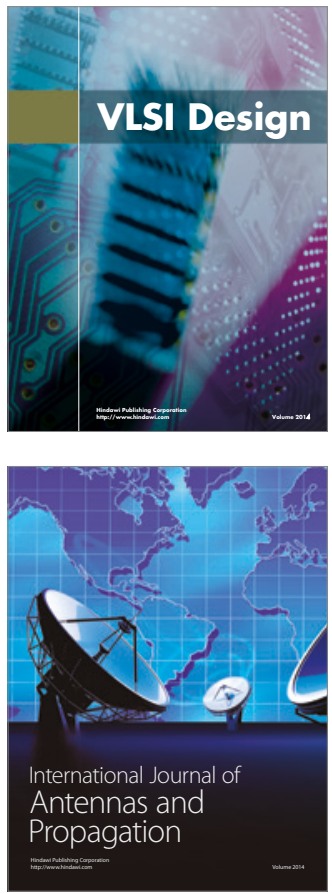

\section{Rotating}

Machinery
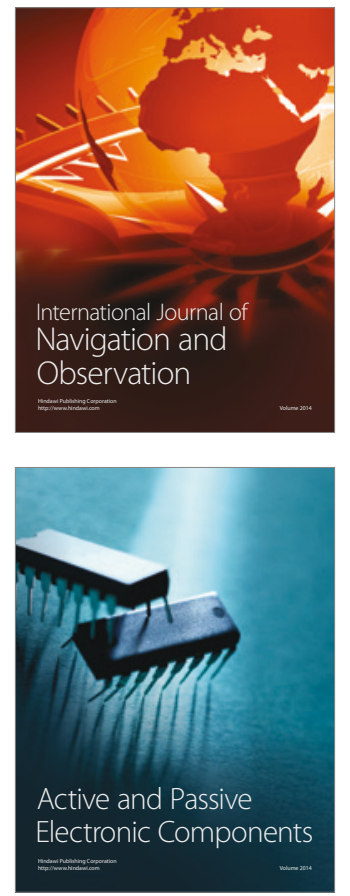
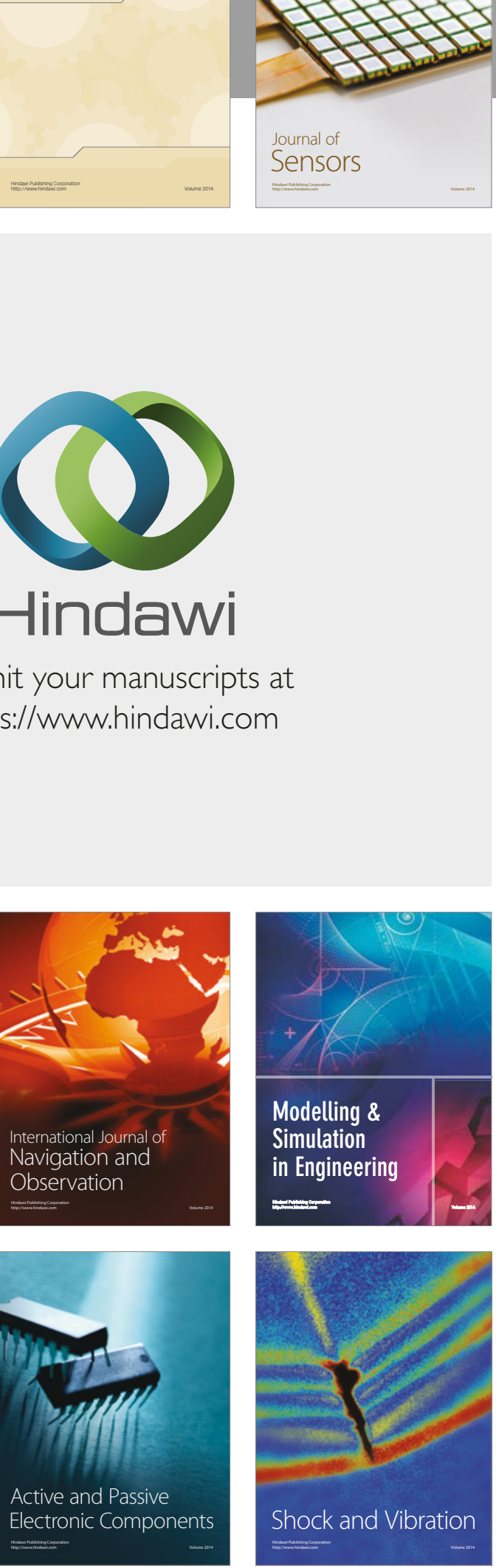
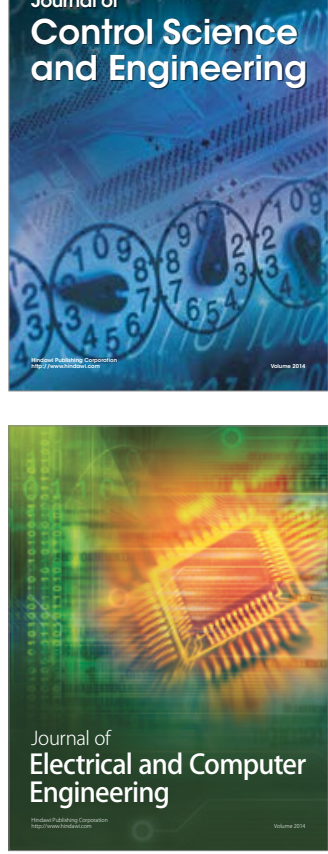

Distributed

Journal of

Control Science

and Engineering
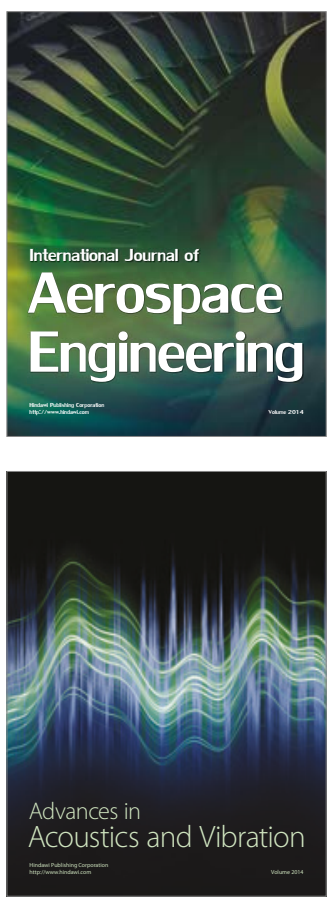

Sensor Networks 